\title{
Influence of thiol stress on oxidative phosphorylation and generation of ROS in Streptomyces coelicolor
}

\author{
Hemendra J. Vekaria, Ratna Prabha Chivukula* \\ Department of Biochemistry, Faculty of Science, The Maharaja Sayajirao University of Baroda, Vadodara, Gujarat, India; \\ hemendravekaria@gmail.com; *Corresponding Author: chivukula_r@yahoo.com
}

Received 14 August 2010; revised 17 September 2010; accepted 21 September 2010.

\begin{abstract}
Thiols play very important role in the intracellular redox homeostasis. Imbalance in the redox status leads to changes in the intracellular metabolism including respiration. Thiol stress, a reductive type of stress can also cause redox imbalance. When Gram-positive bacterium Streptomyces coelicolor was exposed to thiol stress, catalase A was induced. Induction of catalaseA is the consequence of elevation of ROS (reactive oxygen species). The two major sources of reactive oxygen species are Fenton reaction and slippage of electrons from electron transport chain during respiration. Hence, the effect of thiol stress was checked on the rate of oxidative phosphorylation in $S$. coelicolor. We found correlation in the increase of oxidative phosphorylation rate and the generation of ROS, subsequently leading to induction of catalase. It was observed that thiol stress does not affect the functionality of the individual complexes of the ETC, but still there was an increase in the overall respiration, which may lead to generation of more ROS leading to induction of catalase.
\end{abstract}

Keywords: Streptomyces coelicolor; DTT; Oxidative Phosphorylation; CatalaseA; ROS

\section{INTRODUCTION}

According to endosymbiont hypothesis mitochondria evolved from the primitive aerobic bacteria [1]. Similar to mitochondria, bacteria have their electron transport chain located on the inner membrane. There is a lot of flexibility in bacterial electron transport and it varies amongst different bacteria and also shows changes in response to growth conditions. Unlike mitochondria, bacteria generally possess a branched electron transport chain with features, which equip bacteria for successful adaptation to changes in the environment $[2,3]$. Based on the physiology and environment of the bacteria, many organic and inorganic molecules such as nitrate and fumarate, can act as terminal electron acceptors instead of oxygen, thus facilitating anaerobic growth $[4,5]$. The efficiency of oxidative phosphorylation is higher in intact mitochondria as compared to that of bacteria. Hence, overall bacterial oxidative phosphorylation rate is lower than that of intact mitochondria in oxidizing the identical substrates [6,7].

In both prokaryotes and eukaryotes respiratory chain is the major source of reactive oxygen species (ROS) under normal conditions. When E. coli grows exponentially in glucose medium, respiratory chain accounts for as much as $87 \%$ of the total $\mathrm{H}_{2} \mathrm{O}_{2}$ production [8]. This is mainly due to the leakage of electrons at the $\mathrm{NADH}$ dehydrogenase and ubiquinone sites $[9,10]$. When E. coli respiratory vesicles are incubated in vitro with reductive substrates and oxygen, normal electron transport is accompanied by the generation of $\mathrm{O}_{2}{ }^{-}$and $\mathrm{H}_{2} \mathrm{O}_{2}$ [11].

Many studies were carried out to check the effects of oxidizing agents on the respiratory rate of bacteria. In Pseudomonas aeruginosa, exposure to $\mathrm{H}_{2} \mathrm{O}_{2}$ activated the expression of $c y o A B C D$ operon which is a key component of aerobic respiration, by more than 10-fold along with oxidative stress response genes such as catalase katB, alkyl hydroperoxide reductase ahpF, and the thioredoxin reductase II operon [12]. In contrast, there are very few reports on the effects of reductive stress on bacteria. In our earlier studies, with the objective of probing into the effects of reductive stress in bacteria, we chose to expose Streptomyces coelicolor, a Gram positive aerobe to dithiothreitol (DTT). CatalaseA was found to be induced as a consequence of exposure to DTT, which was associated with elevated thiol to disulphide ratio. Although DTT is a very strong reducing agent generally used to reduce proteins, it can induce $\mathrm{H}_{2} \mathrm{O}_{2}$ production in the presence of $\mathrm{O}_{2}$ and transition metal ions [13] through Fenton reaction $[14,15]$. 
In the present work we studied the effect of DTT stress on oxidative phosphorylation, its correlation with ROS generation and subsequently catalaseA induction in the bacterium Streptomyces coelicolor. Further, the elevated ROS levels observed under DTT stress with catalaseA deficient mutant of $S$. coelicolor elucidate the significance of catalaseA induction in wildtype S. coelicolor under DTT stress.

\section{MATERIAL AND METHODS}

\subsection{DTT Treatment and Cell Isolation}

S. coelicolor $\mathrm{A}(3) 2$ cultures were grown to log phase in YEME media at $30^{\circ} \mathrm{C}$ [9] and exposed to $10 \mathrm{mM}$ DTT. After two hours of DTT stress, $10 \mathrm{ml}$ of cells were centrifuged and resuspended in $5 \mathrm{ml}$ of respiration medium (225 mM sucrose, $20 \mathrm{mM} \mathrm{KCl,} 10 \mathrm{mM}$ MOPS pH 7.4, 5 $\mathrm{mM}$ potassium phosphate buffer $\mathrm{pH} 7.4,0.2 \mathrm{mM}$ EDTA and. $0.1 \mathrm{mg} \mathrm{BSA} / \mathrm{ml}$ ) and kept in ice till the assay was performed.

\subsection{Oxidative Phosphorylation}

Measurements of oxidative phosphorylation were carried out at $30^{\circ} \mathrm{C}$ using Clark-type oxygen electrode [16]. After introducing $180 \mu \mathrm{l} \log$ phase culture of S. coelicolor in $1.6 \mathrm{ml}$ of respiratory medium $(0.3 \mathrm{M}$ mannitol, $20 \mathrm{mM}$ KCI, $0.2 \mathrm{mM}$ EDTA, $5.0 \mathrm{mM}$ potassium phosphate buffer and $10 \mathrm{mM}$ Tris/HCI pH7.4) in the electrode chamber, respiration was induced by the addition of specific substrate/s. Final concentrations of the substrates used were: $10 \mathrm{mM}$ glutamate, $10 \mathrm{mM}$ pyruvate $+1 \mathrm{mM}$ malate, $10 \mathrm{mM}$ succinate and $10 \mathrm{mM}$ ascorbate +0.1 mM TMPD. Measurements with the latter two substrates were performed in the presence of $1 \mu \mathrm{M}$ rotenone. State 3 respiration rates initiated by the addition of 80-200 $n$ moles of ADP and state 4 rates ensuing after the depletion of added ADP were recorded. The ADP/O ratio was calculated as $n$ moles of ADP added, divided by $n$ moles of $\mathrm{O}_{2}$ consumed while phosphorylating the added ADP. State 3 and state 4 respirations were calculated as n moles $\mathrm{O}_{2}$ consumed/ min/mg protein, in the presence and absence of ADP respectively. Respiration control ratio is given by state $3 /$ state 4 respiration and ADP phosphorylation rate is determined by $\mathrm{n}$ moles of ATP formed $/ \mathrm{min} / \mathrm{mg}$ protein [16].

\subsection{Generation of CatalaseA Mutants}

CatalaseA mutants were generated by ethyl methane sulphonate (EMS) mutagenesis [17]. Freshly isolated $S$. coelicolor spores were treated with $2 \% \mathrm{v} / \mathrm{v}$ EMS in 0.1 $\mathrm{M}$ potassium phosphate buffer, $\mathrm{pH} 7.0$ for 30 minutes to obtain $90 \%$ mutagenesis frequency. The reaction was terminated by equal volume of $0.2 \mathrm{M}$ sodium thiosulfate. Mutagenized spores were plated on SMA plates and allowed to grow for three days. Fully grown cells were screened for catalase deficient mutants by looking for absence of bubbling followed by $\mathrm{H}_{2} \mathrm{O}_{2}$ overlaying. Catalase deficient mutant colony was identified with very slow bubbling rate and was further confirmed with measurement of catalase activity. Although, the catalase activity in the catalaseA deficient mutant (isolated above) was reduced extensively, its growth was unaffected under normal conditions.

\subsection{Catalase Assay}

For enzyme activity assays, S. coelicolor lysates were prepared as described above. Catalase activity was assayed by monitoring depletion of $\mathrm{H}_{2} \mathrm{O}_{2}$ at $240 \mathrm{~nm}$ every 10 seconds [18]. One $\mathrm{ml}$ of $10 \mathrm{mM} \mathrm{H}_{2} \mathrm{O}_{2}$ solution in 50 $\mathrm{mM}$ potassium phosphate buffer, $\mathrm{pH} 7.0$ was used as assay solution and 5-50 $\mu \mathrm{l}$ of cell extract supernatant was added. Catalase specific activity was expressed as $\mu$ moles of $\mathrm{H}_{2} \mathrm{O}_{2}$ degraded per min per mg protein.

\subsection{Detection of CatalaseA mRNA by RT-PCR}

After two hours of exposure of log phase grown culture of S. coelicolor with DTT, it was pelleted and RNA was isolated with trizole reagent (sigma) followed by DNase treatment. First strand cDNA synthesis was performed with 'First strand cDNA synthesis kit for RTqPCR' from Fermentas using random primers. PCR amplification of catalaseA gene was carried out with forward primer 5'CTG GGA TCC GGT CGG GAAC3' and reverse primer 5'GGT GGA TCC GGT AGT TCT CCG3' PCR product was run on $1.5 \%$ agarose gel and analysed by densitometry using 'Image J' software.

\subsection{Measurement of Hydrogen Peroxide Formation}

$\mathrm{H}_{2} \mathrm{O}_{2}$ formation was monitored from the conversion of 2',7'-dichlorofluorescin diacetate to 2',7'-dichlorofluorescein [19]. Five $\mathrm{ml}$ of mid log phase $S$. coelicolor cells were centrifuged and resuspended in one $\mathrm{ml}$ of $100 \mathrm{mM}$ potassium phosphate buffer, $\mathrm{pH} 7.2$ and incubated with $10 \mathrm{pM}$ dichlorofluorescin diacetate for $30 \mathrm{~min}$ at $30^{\circ} \mathrm{C}$. After loading with dichlorofluorescin diacetate, the cells were washed twice in the same buffer and resuspended in potassium phosphate buffer. The cells were sonicated and centrifuged at $10000 \mathrm{~g}$ for $10 \mathrm{~min}$ to release the cytosolic dye and to remove the debris. Conversion of nonfluorescent dichlorofluorescin diacetate to highly fluorescent dichlorofluorescein was monitored with a Hitachi F-7000 fluorescence spectrophotometer, using excitation and emission wavelengths of 490 and $520 \mathrm{~nm}$ 
respectively.

\section{RESULTS}

\subsection{Effect of DTT on S. coelicolor Respiration}

From Table 1 it is evident that the respiratory rate of $S$. coelicolor in the presence of substrates for the respiratory complexes I, II and III was lower than the respiratory rate reported for mitochondria [1]. Oxygen uptake signal in bacteria was in compliance with that of the mitochondria, but the ADP/O ratio was found to be slightly lower in the presence of all the four substrates. Since $S$. coelicolor is an obligate aerobe it showed induced respiration with $\mathrm{ADP}$ (state 3 respiration) as compared to without ADP (state 4 respiration) similar to the case with mitochondria. The proposed ADP/O ratio establishes the value for $S$. coelicolor and the validity of the assay with bacterial system.

State 3 and state 4 phosphorylation rates were increased in the presence of DTT (Table 1). These observations suggest two possibilities. First, the functionality of the respiratory complexes must have gone up under DTT stress. Second, in order to combat the reducing environment created by DTT, S. coelicolor must have induced the expression of respiratory complexes. Further, there are no significant changes in the $\mathrm{ADP} / \mathrm{O}$ ratio and the respiratory control ratio (RCR) as seen in Table 1, indicating that the functionality of the respiratory complexes remains unaltered in the presence of DTT, ruling out the first possibility. Increased ADP phosphorylation rate in the presence of DTT, therefore suggests the second alternative as the most likely possibility as bacterial systems are more flexible and responsive to external cues [20].

\subsection{Effect of DTT on CatalaseA Expression and Activity}

In wild type $S$. coelicolor catalase activity was elevated to $\sim 80$ fold in the presence of DTT, where as mutant fails to induce it (Figure 1(a)). CatalaseA induction was further checked at the mRNA level by reverse transcriptase-PCR. Under DTT stress catA transcript levels showed an increase compared to WT control, which implies that catalase induction is at transcription level (Figure 1(b)). In catA mutant there was diminished expression of catA transcript accounting for lack of induction of catalase $A$ in response to DTT suggesting that the mutation has occurred in the catA gene itself and probably in the promoter region since it affects the expression rather than activity. The catA mutant shows diminished growth under DTT stress (results not shown).

\subsection{Effect of DTT on S. coelicolor and Generation of $\mathrm{H}_{2} \mathrm{O}_{2}$}

DTT is known to induce catalaseA in S. coelicolor [14]. $\mathrm{H}_{2} \mathrm{O}_{2}$ generated in the presence of DTT due to Fenton reaction as well as increased respiratory rate, appeared to induce catalase A in $S$. coelicolor. Hence, $\mathrm{H}_{2} \mathrm{O}_{2}$ formation was examined for both $\mathrm{S}$. coelicolor wildtype (WT) and catalaseA mutant of $S$. coelicolor in the presence of DTT using 2', 7'dichlorofluorescene diacetate (Figure 2). It was observed that there was no change in the $\mathrm{H}_{2} \mathrm{O}_{2}$ production in S. coelicolor WT, since the induced levels of catalaseA compensate for the increased respiratory rate. In contrast catalase A mutant showed significant increase in $\mathrm{H}_{2} \mathrm{O}_{2}$ production in response to DTT. Hence, it can be concluded that DTT induces ROS generation through augmented respiratory rate.

Table 1. Effect of DTT on oxidative phosphorylation ${ }^{\mathrm{a}}$ rate in S. coelicolor using glutamate, pyruvate + malate, succinate and ascorbate + TMPD as the substrate.

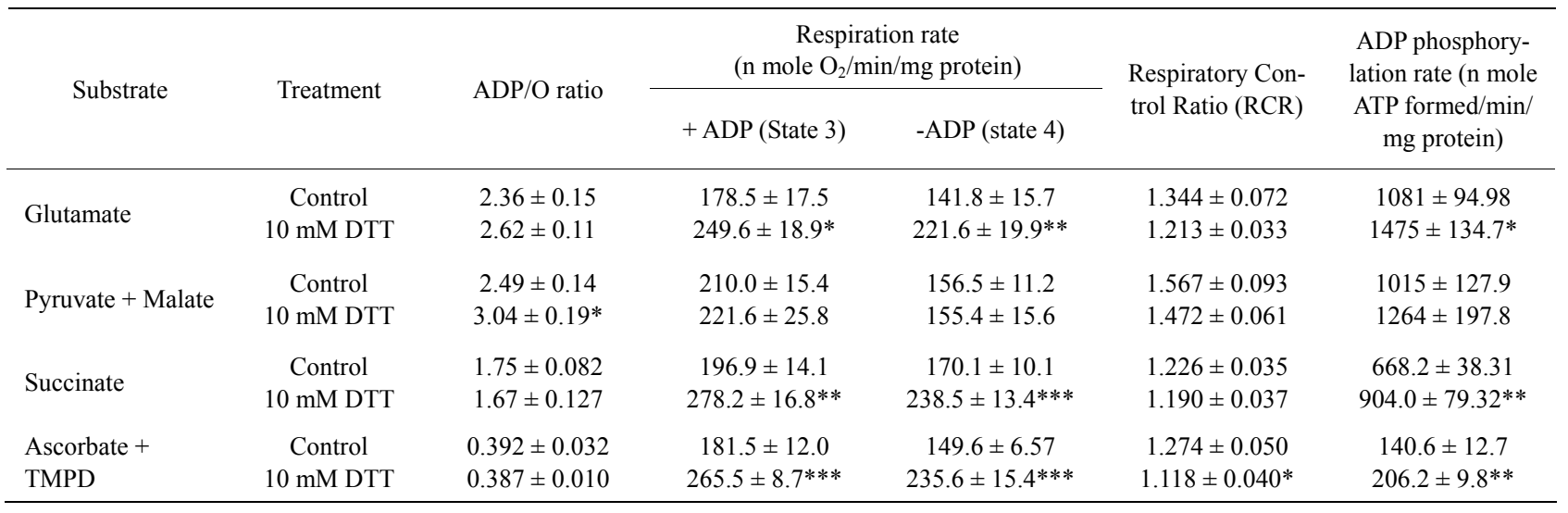

${ }^{a}$ Respiratory rate of log phase grown S. coelicolor control and 10mM DTT treated cultures were measured using Clark type oxygen electrode in the presence and absence of ADP. Based on that ADP/O, RCR and ADP phosphorylation rate were calculated. Values are means of eight to twelve independent experiments \pm SEMs. $* p<0.05 ; * * p<0.01 ; * * * p<0.001$. 


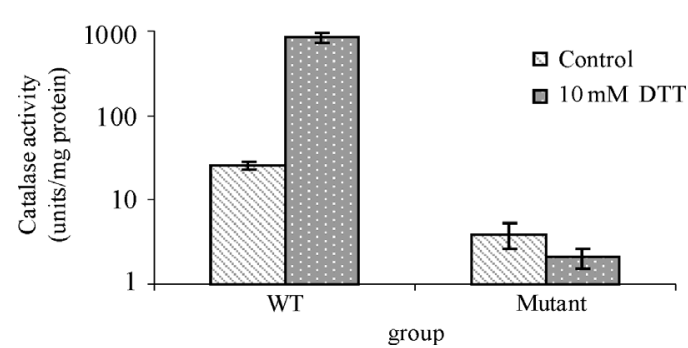

(a)

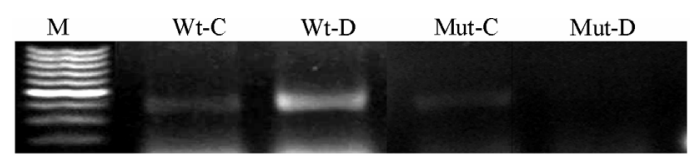

(b)

Figure 1. Effect of DTT on catalase activity or catalaseA expression in WT and catA mutant of S. coelicolor. Log phase grown cultures of WT and mutant were treated with $10 \mathrm{mM}$ DTT (Cross bars) as compare to control(dots) and looked for (a) total catalase activity. (b) catalaseA mRNA expression by RT-PCR. Values are expressed as means of three independent experiments \pm SEMs. Due to large variation in the values $Y$ axis is represented in the $\log$ scale.

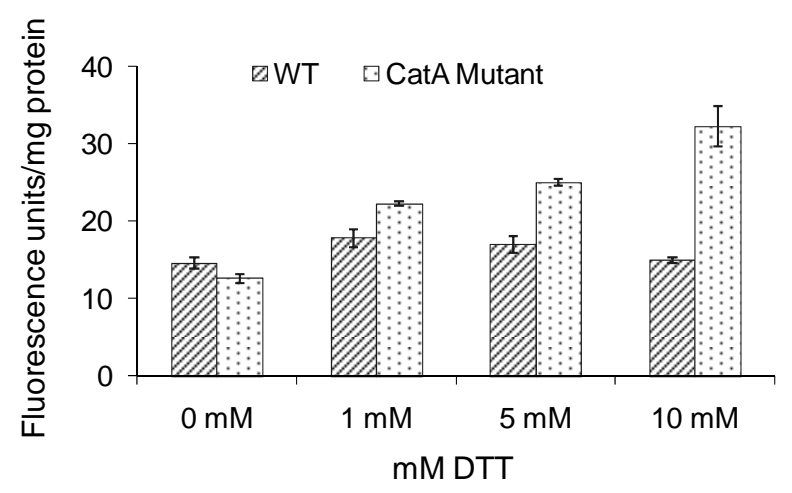

Figure 2. Effect of DTT on ROS generation in WT and catA mutant of $S$. coelicolor. Cross lined and dotted bars indicate ROS levels in WT and catalaseA mutant respectively. Values are expressed as means of six independent experiments \pm SEMs.

\section{DISCUSSION}

In order to carry out all the metabolic processes smoothly, it is very important to maintain the intracellular environment in the reducing state. However, there are some reactions which rely on oxidizing conditions. For example, disulfide bond formation which occurs in endoplasmic reticulum in case of eukaryotes and periplasm in gram negative bacteria. When reducing conditions prevail to the extreme, they may lead to disturbances in the metabolism. For instance under anaerobic conditions, accumulation of reducing equivalents like NADH, GSH are known to cause reductive stress leading to UPR (unfolded protein response). Similar effects can be triggered by reducing thiol containing compounds like homocysteine, glutathione and DTT [21-23]. It was reported earlier that exogenous homocysteine treatment leads to toxicity in eukaryotic systems [24-26]. The above reports are in consent with the observations made by us with $S$. coelicolor in the present study.

Bacteria are versatile and can adapt to extremes of adverse conditions. They, therefore, contain regulatory mechanisms to overcome reductive stress. CatalaseA is found to be induced to a very high level in the presence of DTT stress [14]. Looking at the role of catalaseA, earlier studies in E. coli showed that exposure to NADH, reduced flavins or cysteine exaggerate DNA damage through involvement of the Fenton reaction $[27,28,29]$. In the presence of metals and oxygen, DTT induces free radicals and causes damage to proteins, lipids and DNA [30]. In addition to Fenton reaction, our results show elevated respiration in the presence of DTT cause ROS generation. Reducing environment may lead to reduction of oxygen causing partial hypoxia. In order to compensate for hypoxic stress, there seems to be a rise in the respiratory units on the inner membrane, subsequently leading to increased ADP phosphorylation.

Thiol stress increases rate of oxidative phosphorylation in S. coelicolor. In other words, proportionate increase in the state 3 and state 4 respirations in the presence of DTT signifies augmentation of the overall respiration rate. No detectable changes in the $\mathrm{ADP} / \mathrm{O}$ ratio and the respiratory control ratio (RCR) establish that there is no uncoupling of oxidative phosphorylation in the presence of DTT. The overall ADP phosphorylation rate is increased with all the four substrates elevating ATP synthesis. Respiratory induction leads to elevated levels of ROS. If ROS levels are not kept in check they will affect the growth of the organism as in the case of catalaseA mutant under DTT stress.

In conclusion, the present studies demonstrate that as in oxidative stress, CatalaseA plays a significant role in reductive stress too. But the mechanism and cause involved in the regulation appear to be different from those in the case of oxidative stress. Thus, the two chief effects of increased respiration and ROS generation due to Fenton reaction, act cumulatively to induce catalaseA under reductive stress.

\section{REFERENCES}

[1] Van der Beek, E.G. and Stouthamer, A.H. (1973) Oxidative phosphorylation in intact bacteria. Archives of $\mathrm{Mi}$ crobiology, 89, 327-339.

[2] Niebisch, A. and Bott, M. (2003) Purification of a cytochrome bc-aa3 supercomplex with quinol oxidase activ- 
ity from Corynebacterium glutamicum. Identification of a fourth subunity of cytochrome aa3 oxidase and mutational analysis of diheme cytochrome c1. Journal of Biological Chemistry, 278, 4339-4346.

[3] Schafer, G. and Penefsky, H.S. (2008) Bioenergetics: energy conservation and conversion: Introduction. Results and Problems in Cell Differentiation, 45, IV-VIII.

[4] Kroger, A., Biel, S., Simon, J., Gross, R., Unden, G. and Lancaster, C.R. (2002) Fumarate respiration of Wolinella succinogenes: Enzymology, energetics and coupling mechanism. Biochimica et Biophysica Acta, 1553, 23-38.

[5] Nishimura, T., Vertes, A.A., Shinoda, Y., Inui, M. and Yukawa, H. (2007) Anaerobic growth of Corynebacterium glutamicum using nitrate as a terminal electron acceptor. Applied Microbiology and Biotechnology, 75, 889-897.

[6] Harold, F.M. (1972) Conservation and transformation of energy by bacterial membranes. Bacteriological Reviews, 36, 172-230.

[7] Harold, F.M. (1972) Ion transport and electrogenesis in bacteria. Biochemical Journal, 127, 49-50.

[8] Seaver, L.C. and Imlay, J.A. (2001) Alkyl hydroperoxide reductase is the primary scavenger of endogenous hydrogen peroxide in Escherichia coli. Journal of Bacteriology, 183, 7173-7181.

[9] Gonzalez-Flecha, B. and Boveris, A. (1995) Mitochondrial sites of hydrogen peroxide production in reperfused rat kidney cortex. Biochimica et Biophysica Acta, 1243, 361-366

[10] Gonzalez-Flecha, B. and Demple, B. (1995) Metabolic sources of hydrogen peroxide in aerobically growing Escherichia coli. Journal of Biological Chemistry, 270, 13681-13687.

[11] Messner, K.R. and Imlay, J.A. (1999) The identification of primary sites of superoxide and hydrogen peroxide formation in the aerobic respiratory chain and sulfite reductase complex of Escherichia coli. Journal of Biological Chemistry, 274, 10119-10128.

[12] Salunkhe, P., Topfer, T., Buer, J. and Tummler, B. (2005) Genome-wide transcriptional profiling of the steady-state response of Pseudomonas aeruginosa to hydrogen peroxide. Journal of Bacteriology, 187, 2565-2572.

[13] Netto, L.E. and Stadtman, E.R. (1996) The iron-catalyzed oxidation of dithiothreitol is a biphasic process: hydrogen peroxide is involved in the initiation of a free radical chain of reactions. Archives of Biochemistry and Biophysics, 333, 233-242.

[14] Vekaria, H., Sadagopan, K., Adamec, J., Jarori, G.K. and Prabha, C.R. (2007) Thiol stress induces catalaseA in Streptomyces coelicolor. In: Méndez-Vilas, A., Ed., Communicating Current Research and Educational Topics and Trends in Applied Microbiology, Formatex, 246254.

[15] Held, K.D. and Biaglow, J.E. (1994) Mechanisms for the oxygen radical-mediated toxicity of various thiol-containing compounds in cultured mammalian cells. Radiation Research, 139, 15-23.

[16] Melvin, R. G. and Ballard, J.W. (2006) Intraspecific variation in survival and mitochondrial oxidative phosphorylation in wild-caught Drosophila simulans. Aging Cell, 5, 225-233.

[17] Stonesifer, J. and Baltz, R.H. (1985) Mutagenic DNA repair in Streptomyces. The Proceedings of the National Academy of Sciences Online (US), 82, 1180-1183.

[18] Aebi, H. (1984) Catalase in vitro. Methods in Enzymology, 105, 121-126.

[19] Cathcart, R., Schwiers, E. and Ames, B.N. (1983) Detection of picomole levels of hydroperoxides using a fluorescent dichlorofluorescein assay. Analytical Biochemistry, 134, 111-116.

[20] Richardson, D.J. (2000) Bacterial respiration: A flexible process for a changing environment. Microbiology, 146, 551-571.

[21] Cox, J.S., Shamu, C.E. and Walter, P. (1993) Transcriptional induction of genes encoding endoplasmic reticulum resident proteins requires a transmembrane protein kinase. Cell, 73, 1197-1206.

[22] Kohno, K., Normington, K., Sambrook, J., Gething, M.J. and Mori, K. (1993) The promoter region of the yeast KAR2 (BiP) gene contains a regulatory domain that responds to the presence of unfolded proteins in the endoplasmic reticulum. Molecular Cell Biology, 13, 877-890.

[23] Huang, L.E., Zhang, H., Bae, S.W. and Liu, A.Y. (1994) Thiol reducing reagents inhibit the heat shock response. Involvement of a redox mechanism in the heat shock signal transduction pathway. Journal of Biological Chemistry, 269, 30718-30725.

[24] Starkebaum, G. and Harlan, J.M. (1986) Endothelial cell injury due to copper-catalyzed hydrogen peroxide generation from homocysteine. Journal of Clinical Investigation, 77, 1370-1376.

[25] Stamler, J.S., Osborne, J.A., Jaraki, O., Rabbani, L.E., Mullins, M., Singel, D. and Loscalzo, J. (1993) Adverse vascular effects of homocysteine are modulated by endothelium-derived relaxing factor and related oxides of nitrogen. Journal of Clinical Investigation, 91, 308-318.

[26] Loscalzo, J. (1996) The oxidant stress of hyperhomocyst(e) inemia. Journal of Clinical Investigation, 98, 5-7.

[27] Berglin, E. H., Edlund, M.B., Nyberg, G.K. and Carlsson, J. (1982) Potentiation by L-cysteine of the bactericidal effect of hydrogen peroxide in Escherichia coli. Journal of Bacteriology, 152, 81-88.

[28] Park, S. and Imlay, J.A. (2003) High levels of intracellular cysteine promote oxidative DNA damage by driving the fenton reaction. Journal of Bacteriology, 185, 19421950.

[29] Woodmansee, A.N. and Imlay, J.A. (2002) Reduced flavins promote oxidative DNA damage in non-respiring Escherichia coli by delivering electrons to intracellular free iron. Journal of Biological Chemistry, 277, 3405534066.

[30] Kachur, A.V., Held, K.D., Koch, C.J. and Biaglow, J.E. (1997) Mechanism of production of hydroxyl radicals in the copper-catalyzed oxidation of dithiothreitol. Radiation Research, 147, 409-415. 